\title{
The state of pediatric asthma in Chicago's Humboldt Park: a community-based study in two local elementary schools
}

\author{
Ruchi S Gupta*1,2, Juana Ballesteros³, Elizabeth E Springston 1,2, Bridget Smith4,5, Molly Martin6, Eileen Wang7 and \\ Maureen Damitz ${ }^{8}$
}

\begin{abstract}
Background: Pediatric asthma is a serious public health problem in Chicago and has been designated a high priority concern by residents of Chicago's Humboldt Park, a diverse community area with a large number of Puerto Rican, African American, and Mexican American families.

Methods: In May 2009, following the principles of community-based participatory research, a cross-sectional asthma screening survey was administered to adult caregivers of children attending two Humboldt Park elementary schools. Data were analyzed to determine the prevalence of diagnosed and probable asthma as well as the degree of asthma control among affected children; associations between asthma outcomes and mutable triggers were evaluated.

Results: Surveys from 494 children were evaluated. Physician-diagnosed asthma was reported for $24.9 \%$ of children and probable asthma identified in an additional $16.2 \%$ of children. Asthma was poorly or moderately controlled in $60.0 \%$ of diagnosed children. Smoking occurred inside $25.0 \%$ of households and $75.0 \%$ of caregivers reported idling of vehicles in their community. Report of general stress among caregivers, stress due to community crime, and/or an inability to cope with everyday life were significantly and positively associated with poor asthma morbidity and control among affected children.

Conclusions: Despite high prevalence rates and poor asthma morbidity and control in Humboldt Park, the association of these measures with mutable variables is promising. A community-based asthma intervention to address the issues identified in this study is needed to affect positive change.
\end{abstract}

\section{Background}

Childhood asthma is a serious and growing health concern, with prevalence rates at a historic high and over 9 million children in the U.S. diagnosed in their lifetime $[1,2]$. A costly[3] and potentially debilitating disease, asthma is the most common cause of childhood disability and results in school absenteeism, restricted activity, and increased use of physician and hospital services [4]. Despite improvements in care and increased public awareness, racial and ethnic health disparities persist $[2,5]$. Minority populations in the U.S. have been shown

\footnotetext{
*Correspondence: rugupta@childrensmemorial.org

${ }^{1}$ Institute for Healthcare Studies, Northwestern University Feinberg School of Medicine; 750 N Lake Shore Dr, 10th Fl, Chicago, IL, 60611, USA Full list of author information is available at the end of the article
}

to have disproportionately higher rates of asthma prevalence, adverse health outcomes and disability $[2,4]$.

In Chicago, asthma has been documented as a serious pediatric health concern, with asthma prevalence, hospitalization, and mortality rates well above the national average [6,7]. A recent study on the geographic variability of childhood asthma found prevalence rates ranging from $2 \%$ to $44 \%$ by neighborhood [8]. While neighborhood racial composition explained a large proportion of observed variability, the study concluded further research into neighborhood characteristics was needed to better understand persistent disparities. Several social and community factors -- such as exposure to violence,[9-11] ambient air pollution,[12-14] environmental tobacco smoke,[13,14] indoor allergen levels,[15] and caregiver stress[16] -- have been associated with childhood asthma 
prevalence and morbidity, and may contribute to disparate asthma outcomes.

The purpose of this study was to characterize childhood asthma in Chicago's Humboldt Park neighborhood, a diverse community with a large percentage of Puerto Rican, African American, and Mexican American families. In 2005, community organizers designated asthma a high priority concern and sought partners in academia to address the problem. Multiple initiatives resulted, including the community-academic partnership described herein.

\section{Methods}

The design of this research project utilized communitybased participatory research (CBPR), a collaborative approach to research that addresses a topic of importance to the community and equitably involves academic and community partners in the conduct of research. A CBPR partnership between Children's Memorial Hospital, the Greater Humboldt Park Community of Wellness, the Respiratory Health Association of Metropolitan Chicago, and Rush University Medical Center was formed to evaluate asthma in Humboldt Park by surveying adult caregivers of children attending two public elementary schools.

The Institutional Review Boards of Children's Memorial and Rush University as well as the Chicago Public Schools Research Review Board approved the study protocol. Administration of the survey was conducted with consent of participating schools. Caregiver consent to participate was implicit in the return of completed surveys, which did not include personal identifiers.

\section{Study Sample}

Caregivers of children attending Von Humboldt and Ana Roque de Duprey Elementary schools in Humboldt Park were sought to participate in a cross-sectional survey to evaluate community asthma. Schools were chosen to be representative of the broader demographic characteristics of Humboldt Park (Table 1). Adult caregivers $(\geq 18$ yrs) able to complete a written survey in Spanish or English were eligible and asked to participate. Non-participation was due to inability to complete the survey in Spanish or English, child's absence from the classroom during survey distribution, or failure to return the survey.

\section{Survey Instrument}

The survey instrument was developed using well-established survey methodology $[17,18]$. Initial survey items were constructed by the research team, which included pediatricians, survey researchers, experts in respiratory health, and community leaders. The validity of the instrument was assessed through cognitive interviews with community members to ensure understandability ( $\mathrm{n}=10$, six English/four Spanish). Items were then subject to reliability testing to account for the consistency of participant response over time $(\mathrm{n}=10$, five English/five Spanish). The final survey included 35 items and consisted of questions regarding the child's demographic characteristics, details on home environment, parental report of stress and exposure to violence, parental evaluation of community, assessment of probable asthma,[19] parental report of physician/nurse diagnosed asthma, assessment of asthma control,[20] report of medication usage, and perception of asthma management in the schools.

\section{Study Protocol}

Parents and school staff were informed of the study in a letter from the school principal and community partners. Surveys were distributed in three waves to 36 pre-kindergarten to $8^{\text {th }}$ grade classrooms during May of 2009. Children were instructed to take the survey home to be completed by an adult caregiver. Completed surveys were held by classroom teachers and returned to investigators on a weekly basis. Teachers were instructed to mark students who had and had not returned the survey on their attendance list; physical surveys contained no personal identifying information. Additional surveys were distributed each week to students whose caregivers had not yet responded. Students were given a pencil and eraser when they returned the survey. Classrooms achieving a response rate above $70 \%$ received a pizza party. All teachers were given a $\$ 5$ gift card in appreciation for their time.

\section{Analysis}

Response frequencies were calculated to examine the prevalence of diagnosed and probable asthma. The frequency of reported medication use and response to survey items addressing asthma morbidity and control were calculated for children with a reported diagnosis of asthma. Demographic characteristics and triggers were stratified by the child's asthma status. Finally, to examine the association between asthma outcomes and potential triggers, prevalence ratios (PR) were estimated using Poisson regression models with robust error variances [21].

Respondents who did not indicate whether or not their child had a formal diagnosis of asthma were excluded from analysis $(\mathrm{n}=22)$. Returned surveys with missing responses to other items were included. Accordingly, sample size for each item varied as noted in the tables.

All statistical analyses were performed using STATA 10 (StataCorp LP; College Station, TX) with a Type I error of $\mathrm{p}<0.05$. 
Table 1: Demographic characteristics of Humboldt Park and targeted Humboldt Park elementary

\begin{tabular}{|c|c|c|c|}
\hline Characteristic & Humboldt Park & Von Humboldt Elementary & Ana Roque de Duprey Elementary \\
\hline Population size (n) & 65,836 & 624 & 296 \\
\hline$\%$ Hispanic & 48.0 & 52.4 & 80.5 \\
\hline$\%$ Puerto Rican & 37.3 & -- & -- \\
\hline$\%$ Black & 47.4 & 41.0 & 10.8 \\
\hline$\%$ White & 3.3 & 0.6 & 3.0 \\
\hline$\%$ Asian & 0.4 & 0.0 & 0.9 \\
\hline$\%$ Other race/ethnicity & 0.9 & 6.0 & 4.8 \\
\hline$\%$ Low income ${ }^{i}$ & 88.6 & 97.9 & 97.0 \\
\hline \% Limited English proficiencyii & 31.2 & 4.5 & 33.3 \\
\hline
\end{tabular}

\section{Results}

Surveys were distributed to 874 students and returned for 494 children (56.5\%, Table 2). Children primarily fell between the ages of 7 to 14 years and most reported being Puerto Rican (41.4\%), Black (33.5\%), and/or Mexican (32.5\%). The majority of children received public assistance in the form of Medicaid/AllKids (82.4\%).

\section{Asthma Prevalence, Morbidity, and Control}

One in four caregivers (24.9\%) reported having a child with physician-diagnosed asthma (Table 2). Probable asthma, defined as at least one affirmative response to the Brief Pediatric Screen Plus,[19] was identified in 16.2\% of children without a formal asthma diagnosis. Among children diagnosed with asthma, $48.0 \%$ reported using longterm asthma control medication and $68.3 \%$ quick-relief medication during the month prior to the survey (Table 3); $81.5 \%$ of caregiver's believed their child's medication helped his or her asthma. Asthma was moderately or poorly controlled among $60.0 \%$ of children based on an affirmative response to one or more questions on items 1a-e of the Asthma Therapy Assessment Questionnaire [20]. Roughly 1 in 3 asthmatic children had missed school in the past month and had visited a doctor or the emergency department in the past year due to their illness; $5.4 \%$ of children were admitted to the hospital for an asthma exacerbation in the year prior to the survey.

\section{Frequency of Individual, Community, and Psychosocial Triggers}

Triggers associated with childhood asthma were evaluated for all participants on individual, community, and psychosocial levels. Children tended to live in homes rented by their caregiver (83.6\%). Inside the home, $25.0 \%$ of children were exposed to environmental tobacco smoke and $11.9 \%$ of caregivers observed roaches. Indoor pets were frequently reported, with $21.1 \%$ of children having dogs and $14.0 \%$ having cats.

Half of all participants (51.2\%) reported living in Humboldt Park for five years or more. Caregivers regularly observed vehicles idling on the streets, with $75.0 \%$ reporting idling at least some of the time. Safety in the neighborhood was also a concern, with $63.0 \%$ of caregivers feeling unsafe at least some of the time and the majority (57.4\%) keeping children inside because of violence.

Stress among caregivers was common, with $68.4 \%$ generally stressed and $51.4 \%$ stressed by community crime at least some of the time in the month prior to completing the survey. In the same time period, $48.4 \%$ of caregivers felt that they were unable to cope with their responsibilities at least some of the time. Frequencies for all triggers were either similar or elevated for children with asthma and probable asthma (Table 4).

\section{Associations}

The associations between asthma outcomes and the triggers investigated were estimated using prevalence ratios (PR) obtained from multiple Poisson regression models (Table 5).

\section{Risk of asthma}

Risk of being diagnosed with asthma was significantly higher among children of Black or Puerto Rican race/ethnicity $(\mathrm{PR}=1.51,95 \% \mathrm{CI} 1.11-2.04$ and $\mathrm{PR}=1.39,95 \% \mathrm{CI}$ 1.03-1.89 respectively) and significantly lower among Mexican children ( $\mathrm{PR}=0.56,95 \%$ CI 0.38-0.82) when compared to all other races/ethnicities. A significantly elevated risk of probable asthma was observed only for 
Table 2: Demographic characteristics of children surveyed. ${ }^{i}$

\begin{tabular}{|c|c|}
\hline Variable & Proportion (\%) \\
\hline \multicolumn{2}{|l|}{ Asthma status } \\
\hline Diagnosed asthma $(n=494)$ & 24.9 \\
\hline Probable asthmaii $(n=488)$ & 16.2 \\
\hline \multicolumn{2}{|l|}{ Age (years, $n=491$ ) } \\
\hline $3-4$ & 4.7 \\
\hline $5-6$ & 7.7 \\
\hline $7-8$ & 21.6 \\
\hline $9-10$ & 21.2 \\
\hline $11-12$ & 18.8 \\
\hline $13-14$ & 22.4 \\
\hline $15-16$ & 3.5 \\
\hline \multicolumn{2}{|l|}{ Race/ethnicity $(\mathrm{n}=494)^{\mathrm{iii}}$} \\
\hline Black & 33.5 \\
\hline White & 7.7 \\
\hline Asian & 0.2 \\
\hline Puerto Rican & 41.4 \\
\hline Mexican & 32.5 \\
\hline Other Hispanic & 11.8 \\
\hline Other ethnicity & 1.2 \\
\hline \multicolumn{2}{|l|}{ Insurance type $(n=482)$} \\
\hline Private & 8.7 \\
\hline Medicaid/AllKids & 82.4 \\
\hline Uninsured & 7.7 \\
\hline Other & 1.2 \\
\hline
\end{tabular}

iResponse rate varied by item; $\mathrm{n}$-value listed indicates the total number of responses received for a given item.

iiProbable asthma defined as 1 or more affirmative response to the Brief Pediatric Asthma Screen Plus[19] without having a formal diagnosis of asthma.

iiiMultiple selections were allowed; sum need not equal 100\%.

children whose caregivers observed the highest levels of vehicle idling or experienced stress due to crime most frequently in the month prior to the survey (report of most of the time vs. some/none of the time: $\mathrm{PR}=1.80,95 \% \mathrm{CI}$ 1.18-2.74 and PR $=1.73,95 \%$ CI 1.07-2.79 respectively). Increased risk was not observed among caregivers reporting idling or stress due to crime at lower levels.

\section{Risk of poor morbidity and control in children with asthma}

Among children diagnosed with asthma, those whose caregivers felt unable to cope were more likely to wheeze during the day $(\mathrm{PR}=2.39,95 \%$ CI 1.17-4.88), wheeze while exercising ( $\mathrm{PR}=1.6895 \% \mathrm{CI} 1.03-2.74)$, wheeze at night $(\mathrm{PR}=2.24,95 \% \mathrm{CI} 1.09-4.58)$ and to miss school due to asthma $(\mathrm{PR}=2.45,95 \% \mathrm{CI} 1.21-4.96)$. Wheezing during the day was also more likely among children whose caregivers reported stress due to crime $(\mathrm{PR}=2.07$, 95\% CI 1.05-4.88). Risk of wheeze during exercise was higher for children whose caregivers experienced general stress (PR $=2.05,95 \%$ CI 1.03-4.07).

\section{Discussion}

Pediatric asthma prevalence in Humboldt Park was exceptionally high among children in our study. At $25 \%$, it was more than twice the national average [2]. Also troubling, probable asthma was identified in $17 \%$ of children without a formal diagnosis of asthma. As of 2004, asthma in Humboldt Park was estimated to affect 17\% of children, with probable asthma reported in an additional 11\% of children [22]. Our findings suggest that pediatric asthma in this community remains a pressing concern, and, indeed, may be on the rise. Consistent with previous estimates of racial/ethnic asthma disparities in Chicago,[6,22,23] asthma was significantly more likely among Black and Puerto Rican children compared to all other races/ethnicities. Such findings point once more to the tremendous asthma burden born by minority families in urban environments.

Smoking in households with and without asthmatic children was reported frequently, though not as often as estimated by other studies in Humboldt Park [22]. Multiple studies suggest that exposure to environmental tobacco smoke significantly increases a child's risk of being diagnosed with asthma and experiencing severe asthma symptomatology [24-26]. Encouragingly, a recent study found that changes in exposure to environmental tobacco smoke were significantly associated with changes in pediatric asthma morbidity; decreased exposure was predictive of fewer asthma-related visits to the emergency department, fewer hospitalizations, and decreased exacerbation odds [27]. However, smoking cessation interventions have had limited success, especially in lowincome populations.

Participants in our study, both with and without asthma, frequently reported exposure to other indoor pollutants implicated in asthma outcomes. Specifically, $36 \%$ of children had an indoor dog or cat and $12 \%$ of caregivers reported cockroaches inside the home. Sensitizations to dog or cat or having a dog in one's home have been identified as risk factors for asthma [24,28]. High levels of cockroach and pet allergen levels in the homes of sensitized children have been associated with increased asthma morbidity and greater asthma severity, respectively [29-31].

Exposure to ambient pollutants from traffic exhaust has also been associated with poor respiratory health. For example, children with the highest exposure to traffic exhaust have been shown to have significantly increased 
Table 3: Asthma morbidity and control among children with a reported diagnosis of asthma.

\begin{tabular}{|c|c|}
\hline Variable & Frequency (\%) \\
\hline \multicolumn{2}{|c|}{ Reported use of long-term asthma control medication (past month, $\mathrm{n}=123$ )ii } \\
\hline Inhaled corticosteroidsiii & 28.5 \\
\hline Long-acting beta- 2 agonistsiv & 0.8 \\
\hline Leukotriene modifiers ${ }^{v}$ & 13.0 \\
\hline Cromolyn, nedocromilvi & 0 \\
\hline Combination medicationvii & 5.7 \\
\hline \multicolumn{2}{|c|}{ Reported use of quick-relief medication (past month, $n=123$ )ii } \\
\hline Short-acting beta-2 agonistsviii & 68.3 \\
\hline \multicolumn{2}{|l|}{ Asthma control $(n=100)^{i x}$} \\
\hline Poorly controlled & 27.00 \\
\hline Moderately controlled & 33.00 \\
\hline Well controlled & 40.00 \\
\hline \multicolumn{2}{|c|}{ Child missed school because of asthma? (past month, $n=104$ ) } \\
\hline Yes & 31.7 \\
\hline No & 68.3 \\
\hline \multicolumn{2}{|c|}{ Child visited doctor/ED for asthma? (past year, $\mathrm{n}=103$ ) } \\
\hline Yes & 35.9 \\
\hline No & 64.1 \\
\hline \multicolumn{2}{|c|}{ Child admitted to hospital for asthma? (past year, $\mathrm{n}=104$ ) } \\
\hline Yes & 5.8 \\
\hline No & 94.2 \\
\hline \multicolumn{2}{|c|}{ Believe medications help child's asthma $(n=103) ?$} \\
\hline Yes & 81.5 \\
\hline No & 7.8 \\
\hline Unsure & 10.7 \\
\hline \multicolumn{2}{|c|}{ Comfortable school can manage child's asthma $(n=105) ?$} \\
\hline Not at all & 11.4 \\
\hline Somewhat & 41.0 \\
\hline Very & 47.6 \\
\hline
\end{tabular}

'Response rate varied by item; $\mathrm{n}$-value listed indicates the total number of responses received for a given item.

ii Multiple selections were allowed; sum need not equal $100 \%$.

iiiPulmicort Flexhaler, Azmacort, Qvar (40 and 80 mcg), Pulmicort Respules, Prednisone/Prednisolone, Flovent

ivserevent DPI

vSingulair

vilntal

viiAdvair, Advair MDI

viiiAlbuterol, Proventil, Ventolin, Pro Air, Xopenex, Maxair, Nebulizer

ixLevels of asthma control defined by responses to items 1a-e on the Asthma Therapy Assessment Questionnaire:[20] Poorly controlled T 3

or more affirmative responses; Moderately controlled T 1-2 affirmative responses; Well controlled T 0 affirmative responses

risk of recurrent dry nighttime cough compared to children with lower exposures [32]. A dose-response relationship was also observed in our study, such that only children whose caregivers reported the highest levels of idling were at an increased risk of probable asthma. Notably, reduction in adverse asthma events has been documented in relation to decreased traffic exposures [33].
Emerging literature indicates that stress may play a significant role in pediatric asthma. Research suggests that stress among caregivers is linked to stress response in children $[34,35]$. Childhood stress, in turn, may predict greater asthma severity and morbidity over time. Among children with asthma, there is evidence that chronic stress coupled with an acute incidence of stress substan- 
Table 4: Characteristics of children surveyed presented by asthma status.i

\begin{tabular}{|c|c|c|c|}
\hline Variable & $\begin{array}{r}\text { Proportion (\%), } \\
\text { Diagnosed Asthma }\end{array}$ & $\begin{array}{c}\text { Proportion (\%), } \\
\text { Probable Asthmaii }\end{array}$ & $\begin{array}{r}\text { Proportion (\%), } \\
\text { No Asthma }\end{array}$ \\
\hline \multicolumn{4}{|l|}{ Demographic characteristics } \\
\hline Age (years) & $(n=122)$ & $(n=78)$ & $(n=287)$ \\
\hline $3-4$ & 4.9 & 5.1 & 4.2 \\
\hline $5-6$ & 5.7 & 11.5 & 7.3 \\
\hline $7-8$ & 18.0 & 24.4 & 22.3 \\
\hline $9-10$ & 23.0 & 21.8 & 20.2 \\
\hline $11-12$ & 19.7 & 14.1 & 20.2 \\
\hline $13-14$ & 26.2 & 18.0 & 22.3 \\
\hline $15-16$ & 2.5 & 5.1 & 3.5 \\
\hline Race/Ethnicityiii & $(n=123)$ & $(n=79)$ & $(n=288)$ \\
\hline Black & 43.1 & 34.2 & 29.6 \\
\hline White & 6.5 & 2.5 & 6.3 \\
\hline Asian & 0.0 & 0.0 & 0.4 \\
\hline Puerto Rican & 49.6 & 29.1 & 36.7 \\
\hline Mexican & 21.1 & 17.7 & 37.5 \\
\hline Other Hispanic & 12.2 & 7.6 & 12.9 \\
\hline Other Ethnicity & 1.6 & 0.0 & 1.4 \\
\hline Insurance Type & $(n=121)$ & $(n=73)$ & $(n=284)$ \\
\hline Private & 8.3 & 11.0 & 8.8 \\
\hline Medicaid/AllKids & 81.8 & 78.1 & 83.5 \\
\hline Uninsured & 8.3 & 9.6 & 6.7 \\
\hline Other & 1.7 & 1.4 & 1.1 \\
\hline \multicolumn{4}{|l|}{ Individual triggers } \\
\hline Child lives in: iii & $(n=105)$ & $(n=74)$ & $(n=221)$ \\
\hline Rented home & 85.7 & 77.0 & 84.6 \\
\hline Live with family/friends & 8.6 & 9.5 & 7.7 \\
\hline Owned home & 8.6 & 16.2 & 10.0 \\
\hline Smoking inside child's home? & $(n=105)$ & $(n=74)$ & $(n=220)$ \\
\hline Yes & 23.8 & 29.7 & 24.5 \\
\hline No & 76.2 & 68.9 & 75.0 \\
\hline Unsure & 0.0 & 1.4 & 0.5 \\
\hline Roach inside child's home? & $(n=105)$ & $(n=74)$ & $(n=220)$ \\
\hline Yes & 12.4 & 13.5 & 10.9 \\
\hline No & 84.8 & 78.4 & 88.6 \\
\hline Unsure & 2.9 & 8.1 & 0.5 \\
\hline Pet inside child's home?iii & $(n=104)$ & $(n=72)$ & $(n=220)$ \\
\hline Yes, cat & 15.4 & 15.3 & 12.7 \\
\hline Yes, dog & 24.0 & 19.4 & 20.0 \\
\hline Yes, other pet & 11.5 & 9.7 & 7.3 \\
\hline No & 54.8 & 61.1 & 60.0 \\
\hline \multicolumn{4}{|l|}{ Community triggers } \\
\hline Time in neighborhood? & $(n=122)$ & $(n=79)$ & $(n=286)$ \\
\hline$\geq 5$ years & 54.1 & 51.9 & 47.9 \\
\hline
\end{tabular}


Table 4: Characteristics of children surveyed presented by asthma status.' (Continued)

\begin{tabular}{|c|c|c|c|}
\hline$<5$ years & 45.9 & 48.1 & 52.1 \\
\hline Vehicles idle on street? & $(n=119)$ & $(n=78)$ & $(n=281)$ \\
\hline Most of the time & 25.2 & 31.7 & 16.0 \\
\hline Some of the time & 51.3 & 48.1 & 57.7 \\
\hline None of the time & 23.5 & 20.3 & 26.3 \\
\hline Felt unsafe in neighborhood? & $(n=123)$ & $(n=79)$ & $(n=79)$ \\
\hline Most of the time & 16.3 & 31.7 & 10.6 \\
\hline Some of the time & 53.7 & 50.6 & 46.8 \\
\hline None of the time & 30.1 & 17.7 & 42.6 \\
\hline Ever kept child inside because of violence in community? & $(n=123)$ & $(n=75)$ & $(n=219)$ \\
\hline Yes & 64.1 & 61.3 & 52.5 \\
\hline No & 35.9 & 38.7 & 47.5 \\
\hline \multicolumn{4}{|l|}{ Psychosocial triggers } \\
\hline Felt nervous/stressed? (past month) & $(n=123)$ & $(n=75)$ & $(n=285)$ \\
\hline Most of the time & 15.5 & 11.4 & 13.3 \\
\hline Some of the time & 60.2 & 59.5 & 50.9 \\
\hline None of the time & 24.4 & 29.1 & 35.8 \\
\hline Nervous/stressed by crime in community? (past month) & $(n=123)$ & $(n=79)$ & $(n=285)$ \\
\hline Most of the time & 11.5 & 20.3 & 11.2 \\
\hline Some of the time & 44.3 & 31.7 & 37.6 \\
\hline None of the time & 44.3 & 48.1 & 51.2 \\
\hline Could not cope with responsibilities? (past month) & $(n=102)$ & $(n=73)$ & $(n=220)$ \\
\hline Most of the time & 6.9 & 5.5 & 4.6 \\
\hline Some of the time & 47.1 & 50.7 & 56.8 \\
\hline None of the time & 46.1 & 43.8 & 38.6 \\
\hline
\end{tabular}

iResponse rate varied by item; $n$-value listed indicates the total number of responses received for a given item.

iiProbable asthma defined as 1 or more affirmative response to the Brief Pediatric Asthma Screen Plus[19] without having a formal diagnosis of asthma.

iiiMultiple selections were allowed; sum need not equal 100\%.

tially increases the risk for asthma exacerbations [36]. Symptoms of posttraumatic stress have also been associated with more severe asthma in children [37]. Further, parental stress has been prospectively associated with increased risk of childhood wheeze early in life [16]. In line with these findings, a caregiver's inability to cope with daily life, which may indicate a high level of internalized stress, was most strongly and frequently associated with adverse asthma outcomes among affected children in our study. While not to the same extent, caregiver report of general stress was also associated with poor asthma control. Because the stronger association was not report of stress itself, but report of an inability to cope with stress, instruction in parental coping mechanisms may be an important target for intervention in this population.
The impact of violence on childhood asthma is also becoming more evident. Exposure to violence has been significantly associated with poor health outcomes[38] and is often conceptualized as a source of chronic psychological stress [11]. In urban environments, caregivers' self-report of exposure to violence has been significantly associated with more symptom days and nights among children with asthma, as well as with decreased lung function in general $[10,39]$. Further, the likelihood of asthma has been significantly associated with neighborhood violence, even after controlling for potential confounders [40]. Consistent with these findings, risk of probable asthma and poor asthma morbidity/control in our study was significantly higher among children whose caregivers experienced stress due to community crime. The implication of crime on the community-level illustrates the importance of considering a child's broader 
Table 5: Variables significantly associated with asthma, probable asthma, ${ }^{i}$ and asthma morbidity/control.ii

\begin{tabular}{|c|c|c|}
\hline Variable & Prevalence Ratio (PR) & 95\% Confidence Interval ( $\mathrm{Cl})$ \\
\hline \multicolumn{3}{|l|}{ Risk of asthma diagnosis } \\
\hline Black vs. all other races/ethnicities & 1.51 & $1.11-2.04$ \\
\hline Puerto Rican vs. all other races/ethnicities & 1.39 & $1.03-1.89$ \\
\hline Mexican vs. all other races/ethnicities & 0.56 & $0.38-0.82$ \\
\hline \multicolumn{3}{|l|}{ Risk of probable asthma } \\
\hline High vs. low vehicle idling & 1.80 & $1.18-2.74$ \\
\hline Caregiver stressed by community crime & 1.73 & $1.07-2.79$ \\
\hline \multicolumn{3}{|c|}{ Risk of wheeze during the day (diagnosed asthma only) } \\
\hline Caregiver felt unable to cope & 2.39 & $1.17-4.88$ \\
\hline Caregiver stressed by community crime & 2.07 & $1.05-4.88$ \\
\hline \multicolumn{3}{|l|}{ Risk of wheeze at night (diagnosed asthma only) } \\
\hline Caregiver felt unable to cope & 2.24 & $1.09-4.58$ \\
\hline \multicolumn{3}{|c|}{ Risk of wheeze during exercise (diagnosed asthma only) } \\
\hline Caregiver felt unable to cope & 1.68 & $1.03-2.74$ \\
\hline Caregiver reported general stress & 2.05 & $1.03-4.07$ \\
\hline \multicolumn{3}{|c|}{ Risk of missed school days (diagnosed asthma only) } \\
\hline Caregiver felt unable to cope & 2.45 & $1.21-4.96$ \\
\hline
\end{tabular}

social environment when designing interventions to address pediatric asthma.

The impact of neighborhood stability on asthma outcomes, as measured by length of residence and residence type, was unclear in our study. This association is also unclear in the literature. Prior studies have linked more residential stability both with higher[41,42] and lower[43] asthma rates. Higher asthma rates in more stable communities have been attributed to less thorough and frequent maintenance cleaning in homes occupied for a longer period of time [41]. Conversely, lower asthma rates in more stable communities have been suggested to indicate a better built environment [43].

This study is not without limitations. The cross-sectional study design limits interpretations of causality. The data represent two schools in the Humboldt Park neighborhood with only a moderate response rate and cannot be generalized to the entire community area. However, the sample largely mirrored the demographic characteristics of the schools and of the Humboldt Park community at large, with most respondents from low-income minority homes. Only adult caregivers able to complete the survey in English or Spanish and receiving the survey from their child were able to participate. Due to an administrative error, data on gender was not collected during survey administration and response rate varied by item. Finally, there may have been some selection bias inherent in the recruitment process; those with a child with asthma may have been more inclined to complete the survey, possibly inflating the measurement of asthma.

\section{Conclusions}

Our study suggests that children in Humboldt Park suffer from tremendously high rates of asthma prevalence and adverse outcomes. However, the positive association of these measures with mutable variables suggests ways to reverse these disparities. Although little can be done to address the genetic components of pediatric asthma at this time, interventions on the community level to combat disease have been efficacious and replicated in multiple urban environments [44]. An intervention designed to specifically address the factors implicated in this study and tailored to meet the needs of Humboldt Park is a warranted and much needed next step to work in this community. Encouragingly, Humboldt Park residents are engaged in their community and committed to improving asthma among their children, both essential components of successful asthma interventions [45]. Our work suggests that community-academic partnerships in activated communities such as Humboldt Park can result in effective research initiatives and hold promise for successful and sustainable asthma interventions. 


\section{Competing interests}

The authors declare that they have no competing interests, either real or perceived, in the publication and dissemination of this manuscript.

\section{Authors' contributions}

$R G$ and JB conceived of the study. RG, JB, ES, MM, EW and MD, participated in its design and coordination. RG, JB, ES, and EW oversaw data collection. ES drafted the manuscript, with substantial contributions from RG, JB, BS, MM, EW and MD. BS performed the statistical analysis. All authors read and approved the final manuscript.

\section{Acknowledgements}

We would like to thank Chicago Public Schools and the Humboldt Park community for partnering with us to improve pediatric asthma. This study was made possible by a grant from the Northwestern University Clinical and Translational Sciences Institute (grant UL1RR025741). Our financial sponsors played no role in the development of this manuscript absent their monetary contributions.

\section{Author Details}

1 Institute for Healthcare Studies, Northwestern University Feinberg School of Medicine; 750 N Lake Shore Dr, 10th Fl, Chicago, IL, 60611, USA, 2Smith Child Health Research Program, Children's Memorial Hospital; 2300 Children's Plaza, Box 157, Chicago, IL, 60614, USA, ${ }^{3}$ The Greater Humboldt Park Community of Wellness; 1116 North Kedzie St, Chicago, IL, 60651, USA , ${ }^{4}$ Center for Management of Complex Chronic Care, Edward Hines Jr. VA Hospital; 5000 South 5th Ave, Hines, IL, 60141, USA, 5Health Services Research Program, Loyola University Stritch School of Medicine; 2160 South 1st Ave, Maywood, IL USA 60153, ${ }^{6}$ Departments of Preventive Medicine and Pediatrics, Rush University Medical Center; 1700 W Van Buren St, Suite 470, Chicago, IL, 60612 USA, 7University of Michigan Medical School; 1301 Catherine Rd, Ann Arbor, Ml, 48109, USA and ${ }^{8}$ Respiratory Health Association of Metropolitan Chicago; 1440 W Washingston Blvd, Chicago, IL, 60607, USA

Received: 2 February 2010 Accepted: 24 June 2010

Published: 24 June 2010

\section{References}

1. Akinbami L: The state of childhood asthma, United States, 1980-2005. Adv Data 2006:1-24.

2. Akinbami LJ, Moorman JE, Garbe PL, Sondik EJ: Status of childhood asthma in the United States, 1980-2007. Pediatrics 2009, 123(Suppl 3):S131-145

3. Weiss KB, Sullivan SD: The health economics of asthma and rhinitis. I. Assessing the economic impact. J Allergy Clin Immunol 2001, 107(1):3-8.

4. Newacheck PW, Halfon N: Prevalence, impact, and trends in childhood disability due to asthma. Arch Pediatr Adolesc Med 2000, 154(3):287-293.

5. Miller JE: The effects of race/ethnicity and income on early childhood asthma prevalence and health care use. Am J Public Health 2000, 90(3):428-430.

6. Thomas SD, Whitman S: Asthma hospitalizations and mortality in Chicago: an epidemiologic overview. Chest 1999, 116(4 Suppl 1):135S-141S

7. Weiss KB, Wagener DK: Changing patterns of asthma mortality. Identifying target populations at high risk. JAMA 1990, 264(13):1683-1687.

8. Gupta RS, Zhang X, Sharp LK, Shannon JJ, Weiss KB: Geographic variability in childhood asthma prevalence in Chicago. J Allergy Clin Immunol 2008, 121(3):639-645. e631

9. Wright RJ, Steinbach SF: Violence: an unrecognized environmental exposure that may contribute to greater asthma morbidity in high risk inner-city populations. Environ Health Perspect 2001, 109(10):1085-1089.

10. Wright RJ, Mitchell H, Visness CM, Cohen S, Stout J, Evans R, Gold DR: Community violence and asthma morbidity: the Inner-City Asthma Study. Am J Public Health 2004, 94(4):625-632.

11. Wright RJ: Health effects of socially toxic neighborhoods: the violence and urban asthma paradigm. Clin Chest Med 2006, 27(3):413-421. v

12. Migliaretti $G$, Cavallo F: Urban air pollution and asthma in children. Pediatr Pulmonol 2004, 38(3):198-203.

13. Tatum AJ, Shapiro GG: The effects of outdoor air pollution and tobacco smoke on asthma. Immunol Allergy Clin North Am 2005, 25(1):15-30.
14. Gilmour MI, Jaakkola MS, London SJ, Nel AE, Rogers CA: How exposure to environmental tobacco smoke, outdoor air pollutants, and increased pollen burdens influences the incidence of asthma. Environ Health Perspect 2006, 114(4):627-633. 365

15. Litonjua AA, Carey VJ, Burge HA, Weiss ST, Gold DR: Exposure to cockroach allergen in the home is associated with incident doctordiagnosed asthma and recurrent wheezing. J Allergy Clin Immunol 2001, 107(1):41-47.

16. Wright RJ, Cohen S, Carey V, Weiss ST, Gold DR: Parental stress as a predictor of wheezing in infancy: a prospective birth-cohort study. Am J Respir Crit Care Med 2002, 165(3):358-365.

17. Grant EN, Turner-Roan K, Daugherty SR, Li T, Eckenfels E, Baier C, McDermott MF, Weiss KB: Development of a survey of asthma knowledge, attitudes, and perceptions: the Chicago Community Asthma Survey. Chicago Asthma Surveillance Initiative Project Team. Chest 1999, 116(4 Suppl 1):178S-183S.

18. Sateia MJ, Reed VA, Christian Jernstedt G: The Dartmouth 376 sleep knowledge and attitude survey: development and validation. Sleep Med 2005, 6(1):47-54.

19. Wolf RL, Berry CA, Quinn K: Development and validation of a brief pediatric screen for asthma and allergies among children. Ann Allergy Asthma Immunol 2003, 90(5):500-507.

20. Skinner EA, Diette GB, Algatt-Bergstrom PJ, Nguyen TT, Clark RD, Markson LE, Wu AW: The Asthma Therapy Assessment Questionnaire (ATAQ) for children and adolescents. Dis Manag 2004, 7(4):305-513.

21. Barros AJ, Hirakata VN: Alternatives for logistic regression in crosssectional studies: an empirical comparison of models that directly estimate the prevalence ratio. BMC Med Res Methodol 2003, 3:21.

22. Whitman S, William C, Shah AM: Sinai Health System's Improving Community Health Survey: report I (ten key findings). Chicago: Sinai Health System; 2004.

23. Weiss KB, Shannon JJ, Sadowski LS, Sharp LK, Curtis L, Lyttle CS, Kumar R, Shalowitz MU, Weiselberg L, Catrambone CD, et al:: The burden of asthma in the Chicago community fifteen years after the availability of national asthma guidelines: the design and initial results from the CHIRAH study. Contemp Clin Trials 2009, 30(3):246-255.

24. Lanphear BP, Aligne CA, Auinger P, Weitzman M, Byrd RS: Residential exposures associated with asthma in US children. Pediatrics 2001, 107(3):505-511

25. Cook DG, Strachan DP, Carey IM: Health effects of passive smoking. Thorax 1999, 54(5):469.

26. Yamasaki A, Hanaki K, Tomita K, Watanabe M, Hasagawa Y, Okazaki R, Igishi T, Horimukai K, Fukutani K, Sugimoto Y, et al:: Environmental tobacco smoke and its effect on the symptoms and medication in children with asthma. Int J Environ Health Res 2009, 19(2):97-108.

27. Gerald LB, Gerald JK, Gibson L, Patel K, Zhang S, McClure LA: Changes in environmental tobacco smoke exposure and asthma morbidity among urban school children. Chest 2009, 135(4):911-916.

28. Korppi M, Hyvarinen M, Kotaniemi-Syrjanen A, Piippo-Savolainen $E_{\text {, }}$ Reijonen T: Early exposure and sensitization to cat and dog: different effects on asthma risk after wheezing in infancy. Pediatr Allergy Immunol 2008, 19(8):696-701.

29. Gent JF, Belanger K, Triche EW, Bracken MB, Beckett WS, Leaderer BP: Association of pediatric asthma severity with exposure to common household dust allergens. Environ Res 2009, 109(6):768-774.

30. Rosenstreich DL, Eggleston $P$, Kattan M, Baker D, Slavin RG, Gergen $P$, Mitchell H, McNiff-Mortimer K, Lynn H, Ownby D, et al:: The role of cockroachallergy and exposure to cockroach allergen in causing morbidity among inner-city children with asthma. N Engl J Med 1997, 336(19):1356-1363.

31. Wang J, Visness CM, Calatroni A, Gergen PJ, Mitchell HE, Sampson HA: Effect of environmental allergen sensitization on asthma morbidity in inner-city asthmatic children. Clin Exp Allergy 2009, 39(9):1381-1389.

32. Sucharew $H$, Ryan PH, Bernstein D, Succop P, Khurana Hershey GK, Lockey J, Villareal M, Reponen T, Grinshpun S, Lemasters G: Exposure to traffic exhaust and night cough during early childhood: the CCAAPS 422 birth cohort. Pediatr Allergy Immunol 2009.

33. Friedman MS, Powell KE, Hutwagner L, Graham LM, Teague WG: Impact of changes in transportation and commuting behaviors during the 1996 Summer Olympic Games in Atlanta on air quality and childhood asthma. JAMA 2001, 285(7):897-905. 
34. Vallee M, Mayo W, Dellu F, Le Moal M, Simon H, Maccari S: Prenatal stress induces high anxiety and postnatal handling induces low anxiety in adult offspring: correlation with stress-induced corticosterone secretion. J Neurosci 1997, 17(7):2626-2636.

35. Liu D, Diorio J, Tannenbaum B, Caldji C, Francis D, Freedman A, Sharma S, Pearson D, Plotsky PM, Meaney MJ: Maternal care, hippocampal glucocorticoid receptors, and hypothalamic-pituitary-adrenal responses to stress. Science 1997, 277(5332):1659-1662.

36. Sandberg S, Paton JY, Ahola S, McCann DC, McGuinness D, Hillary CR, Oja $\mathrm{H}$ : The role of acute and chronic stress in asthma attacks in children. Lancet 2000, 356(9234):982-987.

37. Vanderbilt D, Young R, MacDonald HZ, Grant-Knight W, Saxe G, Zuckerman B: Asthma severity and PTSD symptoms among inner city children: a pilot study. J Trauma Dissociation 2008, 9(2):191-207.

38. Graham-Bermann SA, Seng J: Violence exposure and traumatic stress symptoms as additional predictors of health problems in high-risk children. J Pediatr 2005, 146(3):349-354.

39. Walker J, Lewis-Land C, Kub J, Tsoukleris M, Butz A: The effect of violence on asthma: are our children facing a double-edged sword? $J$ Community Health 2008, 33(6):384-388.

40. Walker J, Lewis-Land C, Kub J, Tsoukleris M, Butz A: The association between community crime and childhood asthma prevalence. Ann Allergy Asthma Immunol 2010, 104(4):299-306.

41. Peters JL, Levy Jl, Rogers CA, Burge HA, Spengler JD: Determinants of allergen concentrations in apartments of asthmatic children living in public housing. J Urban Health 2007, 84(2):185-197.

42. Gupta RS, Zhang X, Sharp LK, Shannon JJ, Weiss KB: The protective effect of community factors on childhood asthma. J Allergy Clin Immunol 2009, 123(6):1297-1304. e1292

43. Rauh VA, Chew GR, Garfinkel RS: Deteriorated housing contributes to high cockroach allergen levels in inner-city households. Environ Health Perspect 2002, 110(Suppl 2):323-327.

44. The Center for Managing Chronic Disease: Asthma Health OutcomesProject, asthma programs with an environmental component: a review of the field and lessons for success. Ann Arbor, MI: The University of Michigan; 2007.

45. Peterson JW, Lachance LL, Butterfoss FD, Houle CR, Nicholas EA, Gilmore $L A$, Lara $M$, Friedman AR: Engaging the community in coalition efforts to address childhood asthma. Health Promot Pract 2006, 7(2 Suppl):56S-65S

Pre-publication history

The pre-publication history for this paper can be accessed here: http://www.biomedcentral.com/1471-2431/10/45/prepub

doi: $10.1186 / 1471-2431-10-45$

Cite this article as: Gupta et al., The state of pediatric asthma in Chicago's Humboldt Park: a community-based study in two local elementary schools BMC Pediatrics 2010, 10:45

Submit your next manuscript to BioMed Central and take full advantage of:

- Convenient online submission

- Thorough peer review

- No space constraints or color figure charges

- Immediate publication on acceptance

- Inclusion in PubMed, CAS, Scopus and Google Scholar

- Research which is freely available for redistribution

Submit your manuscript at www.biomedcentral.com/submit
C Biomed Central 